Article

\title{
Influence of Age and Nutritional Status on Flight Performance of the Asian Tiger Mosquito Aedes albopictus (Diptera: Culicidae)
}

\author{
Christian Kaufmann ${ }^{1,2, *}$, Lauren F. Collins ${ }^{1}$ and Mark R. Brown ${ }^{1}$ \\ 1 Department of Entomology, University of Georgia, Athens, GA 30602, USA; \\ E-Mails: 1fkelly@bu.edu (L.F.C.); mrbrown@uga.edu (M.R.B.)
}

2 Swiss National Centre for Vector Entomology, Institute of Parasitology, University of Zürich, CH-8057 Zürich, Switzerland

* Author to whom correspondence should be addressed: E-Mail: anopheles@swissonline.ch; Tel.: +41-44-635-85-01; Fax: +41-44-635-89-07.

Received: 11 April 2013; in revised form: 4 June 2013 / Accepted: 25 June 2013 /

Published: 26 July 2013

\begin{abstract}
The Asian tiger mosquito, Aedes albopictus, is a competent vector for arboviruses and recently was implicated as the vector of the first autochthonous cases of dengue and chikungunya in southern Europe. The objective of this study was to analyze the flight performance of female Ae. albopictus of different ages that were starved, sugar-fed, or sugar-fed and blood-fed, using flight mills. After three days of starvation post emergence, females flew an average distance of $0.7 \pm 0.5 \mathrm{~km}$ in $1.9 \pm 1.5 \mathrm{~h}$ during a $16 \mathrm{~h}$ trial period, whereas sugar- or sugar- and blood-fed females of this age covered a significantly higher distance of around $3 \mathrm{~km}$ with a mean total flight time of around $6 \mathrm{~h}$. The age of females (up to four weeks) had no effect on performance. The average of maximal continuous flight segments of sugar-fed $(2.14 \pm 0.69 \mathrm{~h})$ and blood-fed $(3.17 \pm 0.82 \mathrm{~h})$ females was distinctly higher than of starved females $(0.38 \pm 0.15 \mathrm{~h})$ of which most flyers $(83 \%)$ performed maximal flight segments that lasted no longer than $0.5 \mathrm{~h}$. Overall, the results for the laboratory monitored flight performance of Ae. albopictus confirm their ability to disperse a few kilometres between breeding site and host.
\end{abstract}

Keywords: Aedes albopictus; flight potential; distance; vector; mosquito 


\section{Introduction}

The Asian tiger mosquito Aedes albopictus (Skuse) has spread from Southeast Asia to Europe, the Middle East, Africa and the Americas over the past 30 years. This remarkable expansion was aided by the global trade of goods, especially scrap tires [1] and plants like lucky bamboo [2], carrying mosquito eggs or larvae. In Europe, this species was first identified in Albania in 1979 [3] and is now widely established in southern Europe [4-6]. In 1985, Ae. albopictus was found in Texas, USA [7], and by the 1990s, it had nearly displaced the yellow fever mosquito, Ae. aegypti, across the southeastern U.S., although in a few areas both species coexist [8]. Aedes albopictus is a competent vector to transmit dengue virus, chikungunya virus, and other arboviruses to humans [8]. To date, it has not been implicated in dengue or chikungunya epidemics in the Americas, but it was the evident vector in recent outbreaks of chikungunya fever on islands of the Indian Ocean and in Italy [9-11]. In southern France, two independent cases of autochthonous dengue and two of chikungunya fever that occurred in the autumn of 2010 were transmitted by this species [12]. Arboviruses are disseminated widely by travelling infected humans $[13,14]$, but their local transmission is dependent on the availability of susceptible mosquito species such as Ae. albopictus [15]. The flight performance of susceptible female mosquitoes is an important determinant of their host-seeking ability, dispersal potential, and longevity [16], all of which affect vectorial capacity. Laboratory experiments using flight mills are one option to analyze flight performances, and this approach has been pursued in past studies [16-19]. More recently, differences between the flight performance of wild type and transgenic males of Ae. aegypti were obtained with flight mills [20]. The goals of our study were to determine the effects of aging and nutritive states on the flight performance of female Ae. albopictus, thus providing insight into the potential dispersal capability of this important arbovirus vector and its displacement of Ae. aegypti in the U.S.

\section{Material and Methods}

Mosquitoes: The colony of Ae. albopictus (originally collected by Prof. Hans Briegel in Louisiana, U.S. and maintained as a laboratory strain over 20 years) was held at $26 \pm 1{ }^{\circ} \mathrm{C}$ and $85 \pm 10 \%$ relative humidity under long-day conditions ( $16 \mathrm{~h}$ light, $8 \mathrm{~h}$ dark). For egg production, females were allowed to feed on an anesthetized rat. After hatching, first instar larvae were transferred to trays $(34 \times 21 \times 5 \mathrm{~cm}$; 200-250 larvae/tray) containing $700 \mathrm{~mL}$ distilled water and fed a daily regimen of pulverized Tetramin $^{\circledR}[21]$ to support optimal growth and development. Pupae were collected into shallow cups that were placed into plexiglas and wire-screen walled cages $(24 \times 19 \times 18.5 \mathrm{~cm})$ to contain emerging adults (200-300/cage). Adults had continuous access to distilled water (starved) or to $10 \%$ fructose solution (sugar-fed), depending on experimental conditions. In addition, 3 and 21 day old sugar-fed mosquitoes were given access to a human arm for blood feeding, and within 10 min after taking a full meal, the blood-fed females were used in the trials.

Flight performance: For the flight experiments, only single females (chilled on ice) with similar wing lengths between 3.2 to $3.6 \mathrm{~mm}$ (measured from the alula to the tip, including the fringe) were attached to an arm (using hot wax) and flown on flight mills (Figure 1) constructed according to Rowley and colleagues [22]. The circumference of the flight path is $32.7 \mathrm{~cm}$, and the number of 
revolutions was recorded by a computer at $30 \mathrm{~s}$ intervals. Flight experiments usually started around noon and lasted for $16 \mathrm{~h}$ at room temperature $\left(24 \pm 2{ }^{\circ} \mathrm{C}\right)$ under summer light conditions. From each of several cohorts, 20 females were staged for each of the different nutritional conditions and ages. Females were subjected to only one flight trial, and data from females flying $<0.5 \mathrm{~km}$ were not included for analysis, because poor flights most often indicated faulty mounting onto the flight arm. After each flight trial, the following data were calculated for each female: total distance flown during the test period, average active flight time (i.e., sum active flight time in the $30 \mathrm{~s}$ interval), flight speed, and temporal flight/rest pattern (i.e., segments of continuous flights or erratic flight pulses). The flight data was analyzed with PASW Statistics 18 software [23] using ANOVA, Tukey-HSD (alpha =0.05) and error terms were given with \pm STDEV.

Figure 1. Flight mill (12 cm diameter $\times 6 \mathrm{~cm}$ height) with an aluminium drum (d), four arms of steel wire, and a photointerrupter (p). A female mosquito is attached to the end of one arm with wax on its scutum. The photointerrupter transmits data to a computer.

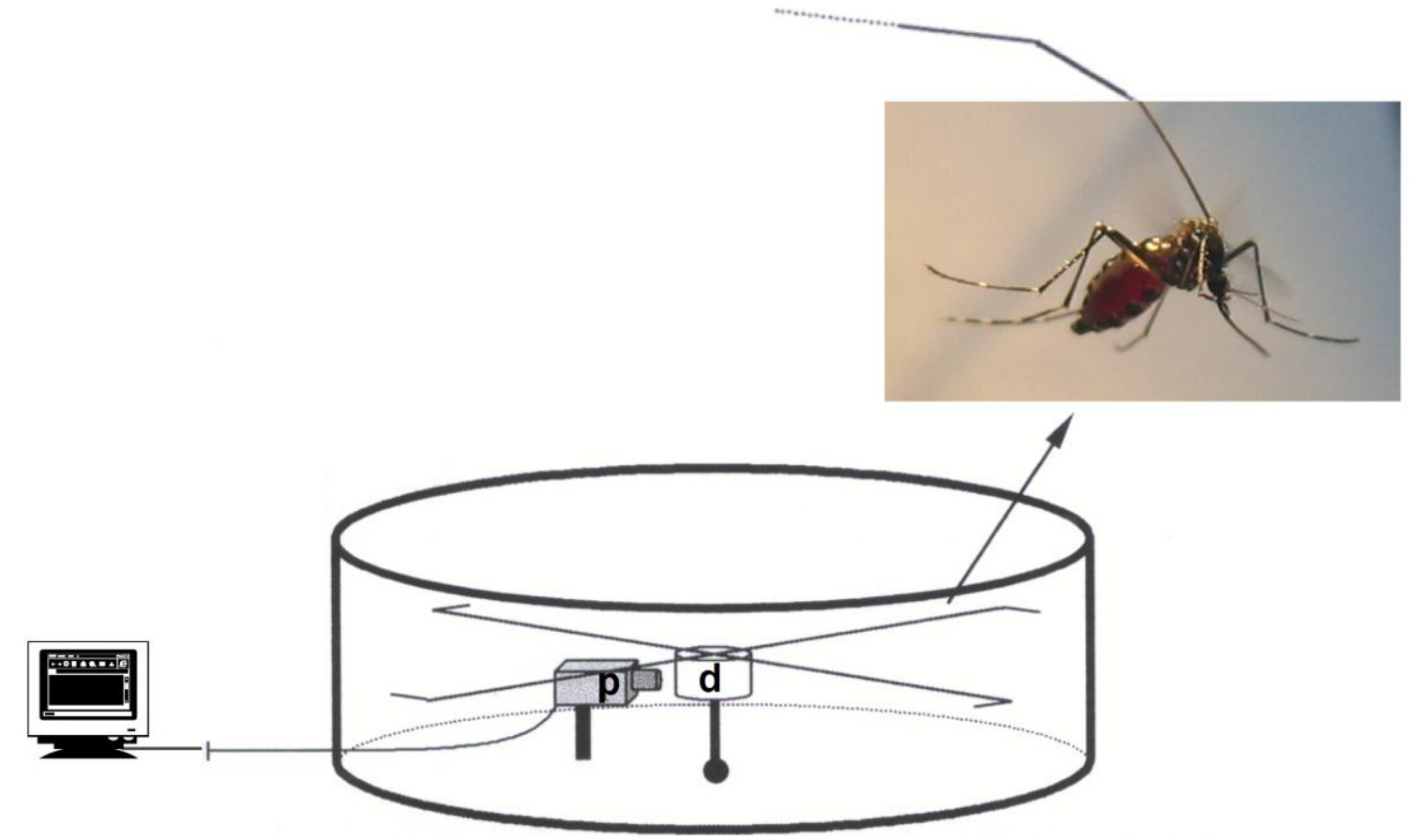

\section{Results}

When tested on the first day post eclosion, starved and sugar-fed Ae. albopictus females flew an average distance of $0.4 \pm 0.3 \mathrm{~km} / 16 \mathrm{~h}$ (Figure 2). After 3 days of starvation, females covered an average distance of $0.7 \pm 0.5 \mathrm{~km} / 16 \mathrm{~h}$, which is not significantly different from that of 1 day old starved females. By day 3, sugar-fed females flew a much greater distance of $2.7 \pm 1.2 \mathrm{~km} / 16 \mathrm{~h}$, and females with continuous access to the sugar solution maintained this flight ability for up to 4 weeks (overall average distance of $2.6 \pm 1.4 \mathrm{~km} / 16 \mathrm{~h}$; Figure 2). Three day old blood-fed females flew $3.8 \pm 2.3 \mathrm{~km} / 16 \mathrm{~h}$ (Figure 2), which is not significantly different than the distance flown by sugar-fed females of the same age. The flight of 3 week old blood-fed females was again not significantly different from that of similarly aged, sugar-fed females. 
Figure 2. Total flight distances (bars) and average flight times (circles above the bars) for starved (water only; white bars), sugar-fed (10\% fructose solution; black bars), and blood-fed (sugar-fed with a blood meal immediately before the experiment; grey bars) females of different ages. Data shown are means $( \pm$ STDEV) from $n=14-19$ for each treatment recorded on flight mills (Oneway Anova, Tukey-HDS, $p \leq 0.05$; for distance and flight time).

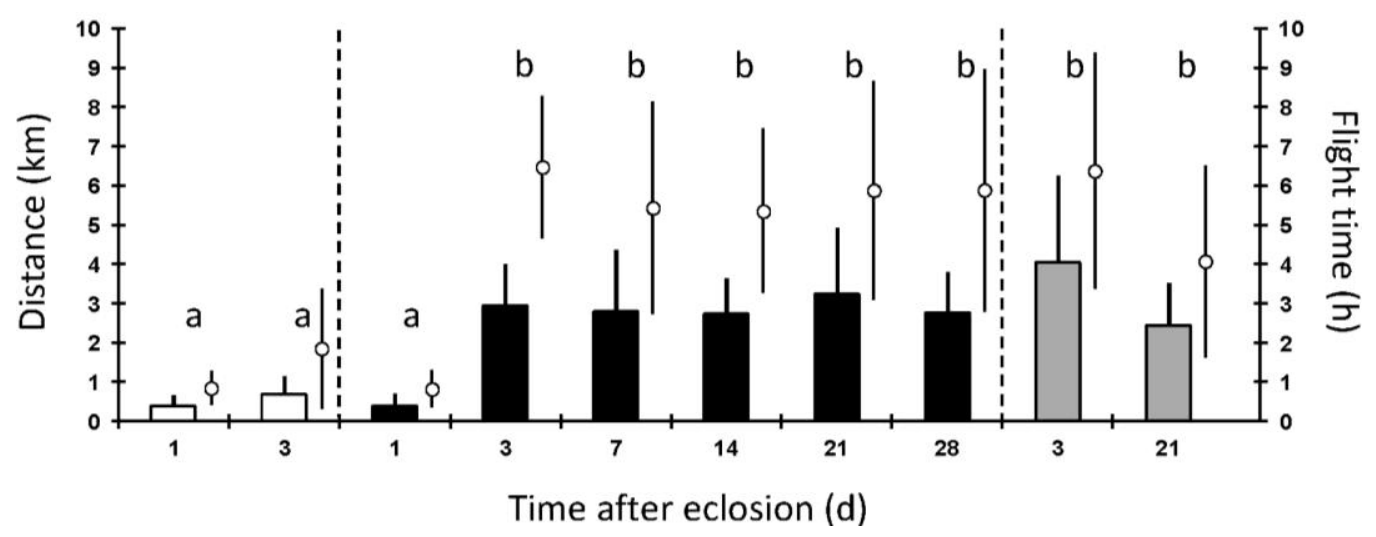

The average flight time for the different groups of experimental females is presented in Figure 2, and the same trends described above are evident. One day old females starved or sugar-fed spent a similar time flying $(0.85 \pm 0.44 \mathrm{~h}$ and $0.82 \pm 0.48 \mathrm{~h}$, respectively). The flight times of 3 day old sugar- or blood-fed females did not statistically differ $(5.84 \pm 2.20 \mathrm{~h}$ and $6.03 \pm 3.22 \mathrm{~h}$, respectively), but the times were significantly longer $(p \leq 0.05)$ than those of starved females $(1.85 \pm 1.53 \mathrm{~h})$. At 3 weeks post eclosion, both sugar- and blood-fed females had similar flight times as that of day 3 females $(p>0.5)$. Blood-fed females flew an average of $3.84 \pm 2.50 \mathrm{~h}$, which was less than that of sugar-fed sisters $(5.06 \pm 3.05 \mathrm{~h})$, though not significantly different. Within the three feeding treatments, the mean flight speed of differently aged mosquitoes was similar. However, starved and sugar-fed females flew significantly slower than their blood-fed sisters $(0.43 \pm 0.17 \mathrm{~km} / \mathrm{h}$, $0.50 \pm 0.18 \mathrm{~km} / \mathrm{h}$, and $0.68 \pm 0.23 \mathrm{~km} / \mathrm{h}$, respectively).

The average of maximal continuous flight segments per flight trial of starved females $(0.38 \pm 0.15 \mathrm{~h})$ was significantly different $(p \leq 0.05)$ from that of sugar- and blood-fed females $(2.14 \pm 0.69 \mathrm{~h}$ and $3.17 \pm 0.82 \mathrm{~h}$, respectively). The data for this parameter were not significantly different for the two latter groups. Under starvation, most females (83\%) performed maximal flight segments that lasted no longer than $30 \mathrm{~min}$ (Table 1). Only two starved females (11\%) showed flight segments of more than $30 \mathrm{~min}$ but less than $1 \mathrm{~h}$, and the best flying starved female had a continuous flight segment of $1.28 \mathrm{~h}$. A distinctly different pattern was obvious for the sugar- and the blood-fed females, which generally flew continuously for longer than $1 \mathrm{~h}$ (76 and 88\%, respectively), but such flights were beyond the capability of all but one starved female.

Representative flight recordings for individual 3 day old starved, sugar- or blood-fed females are presented in Figure 3. After mounting, females immediately started to fly. The duration of the initial flight was less than half an hour for most (72\%) of the starved females, and thereafter, they took short flight spurts and needed longer resting periods (Figure 3A). Initial non-stop flights lasted more than $1 \mathrm{~h}$ for $37 \%$ of sugar-fed females, and then, they took fewer but longer continuous flights (Figure 3B), as compared with their starved sisters (Table 1). Blood-fed females were capable of long continuous 
flights $(>3.5 \mathrm{~h}$ ) with a majority (82\%) flying more than $1 \mathrm{~h}$ non-stop for the initial flight (Figure 3C). One remarkably energetic blood-fed female flew nearly $11 \mathrm{~h}$ without any substantial interruption (Figure 3D).

Table 1. Percentage of maximal continuous flight segments for female Ae. albopictus (day 3 post eclosion) in different nutritional states.

\begin{tabular}{cccccc}
\hline & \multicolumn{5}{c}{ Maximal continuous flights (h) } \\
\hline & $<0.5$ & $0.5-1$ & $1-2$ & $2-4$ & $>4$ \\
Feeding condition ${ }^{1}$ (number of fliers) & & \multicolumn{5}{c}{$\%$} \\
Starved (18) & 83 & 11 & 6 & 0 & 0 \\
Sugar-fed (16) & 6 & 19 & 25 & 37 & 13 \\
Blood-fed (17) & 6 & 6 & 12 & 41 & 35 \\
\hline
\end{tabular}

${ }^{1}$ Starved: access to water only; sugar-fed: access to $10 \%$ fructose solution; blood-fed: sugar-fed females that took a blood meal immediately before the trial.

Figure 3. Representative flight profiles for individual female Ae. albopictus (3 days old) over $16 \mathrm{~h}$ with total distance given at the top right, and recorded flight speed given as $\mathrm{m} / \mathrm{min}$ on the $\mathrm{X}$ axis. (A) Starved (access to water only), (B) sugar-fed (10\% fructose solution), and $(\mathbf{C})$ blood-fed immediately before the experiment (prior access to $10 \%$ fructose solution). (D) Exceptional flight of a blood-fed female.
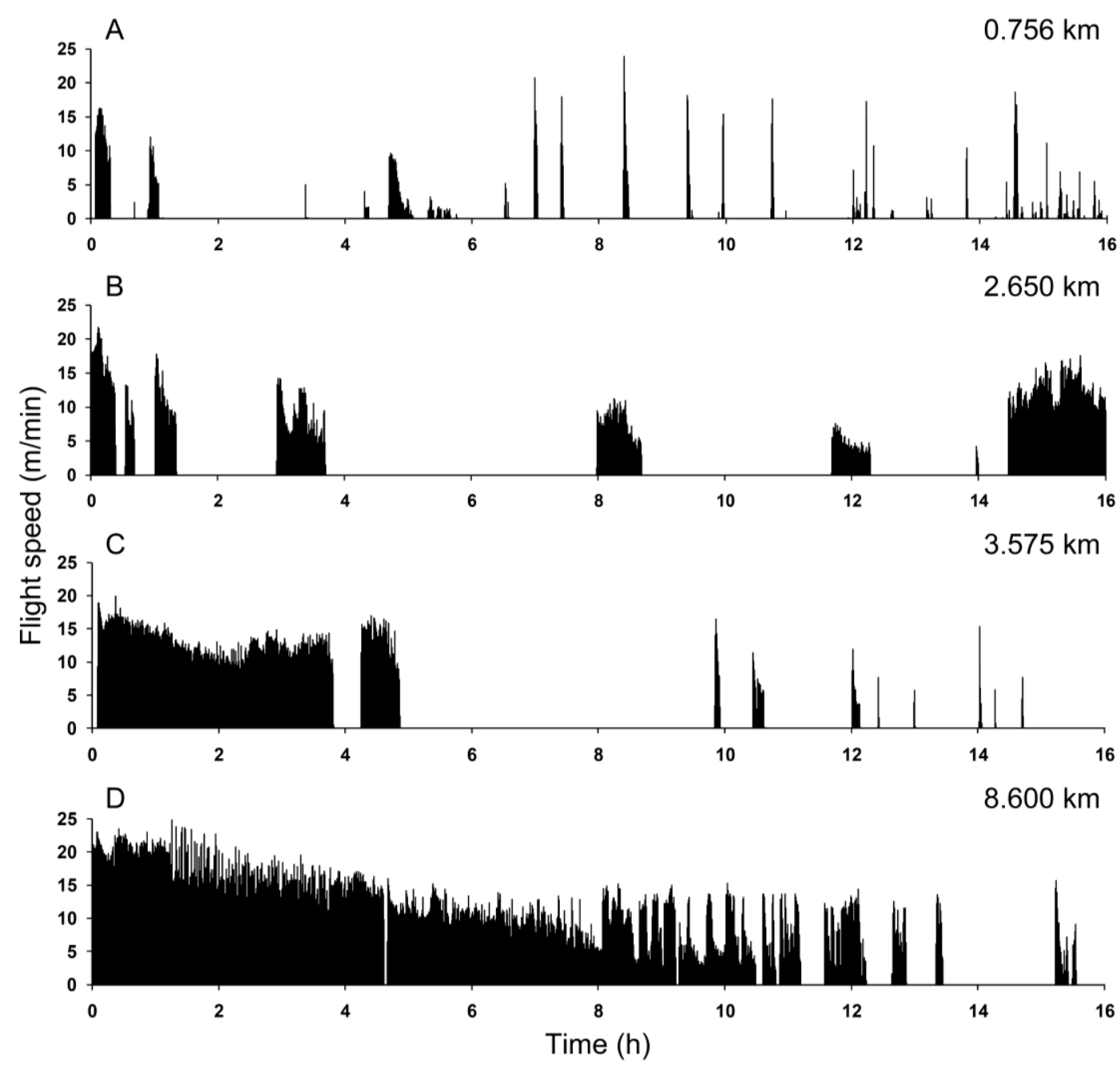


\section{Discussion and Conclusions}

This is the first study to evaluate the flight performance of female Ae. albopictus using a flight mill system and to determine the effects of different nutritional states. Females starved (access to water only) up to three days after emergence exhibited short and fast flight bursts that may indicate searches for natural sugar sources needed to sustain flight after eclosion. However, females given immediate access to sugar did not exhibit increased flight performance at day 1, as compared to starved mosquitoes, but females given sugar solution for 3 days flew a significantly greater distance. This result may indicate that during the first day after eclosion the ingested sugar was stored as glycogen and lipid and later metabolized for flight fuel [21]. As well, the ingested sugar and its metabolites may provide energy for the maturation of the "mosquito flight machinery" and other organs [19,24], which restricts the flight range during the first day after eclosion. Further, the uptake of sugar by $A e$. albopictus was shown to be crucial for increased longevity, whereas blood fed and starved females had similar and shorter life-spans [25]. In contrast, the survival and strong flight performance of the highly anthropophilic African malaria vector Anopheles gambiae, a facultative sugar feeder, was not enhanced or dependent on ingested sugar [16,26].

Aedes albopictus females provided with sugar and then a blood meal did not show a different flight performance (time and distance flown) than those given sugar only; similar results were observed for Ae. aegypti [17]. However, the flight speed of Ae. albopictus was affected by nutritional state, i.e., blood-fed females flew faster than the starved and the sugar-fed ones. This trend suggests blood-fed mosquitoes have longer continuous flights, and therefore less low-speed initiations and terminations of flights. The natural behaviour of mosquitoes after a blood meal is to search for a resting place to digest the blood and complete egg development. Approximately 35 to $50 \%$ of the digested blood metabolites are used for egg production in this mosquito species [21], and some of the remaining metabolites may be used as flight fuel. As shown here, blood-fed females are capable of long continuous flights, e.g., $35 \%$ exhibited flights lasting longer than $4 \mathrm{~h}$ (Table 1), and most flew longer than $1 \mathrm{~h}$ immediately after mounting onto the flight mill. In this situation, females appear to commence searching for a resting place but continuously fly when forced to be air-borne tethered on the flight mill system. How this affects blood digestion, apportionment of metabolites (sugars and/or lipids), or egg development is yet to be resolved. However, it shows clearly that the blood does not shut down the female's ability to fly and escape a predator or other disruption.

Comparative experiments with similarly aged and nourished mosquitoes have been performed with Ae. vexans, Ae. aegypti, An. gambiae and An. atroparvus [16-18]. In general, Aedes spp. females are stronger fliers (mean distance of around $7 \mathrm{~km}$ ) than the Anopheles spp., which flew about half this distance. These experiments were done in the same laboratory with the same flight mill equipment. In our study, sugar-fed Ae. albopictus females flew an average of $3 \mathrm{~km}$, which is comparable to that of the Anopheles spp., and this discrepancy in Aedes spp. performance may reflect different rearing conditions (e.g., larval diet, climatic environment, et cetera) and the newness of the flight mills. Because Ae. albopictus has largely replaced Ae. aegypti in the southeastern U.S., their developmental and behavioural characteristics are often compared [27-29]. One of our hypotheses for this phenomenon was that Ae. albopictus is a stronger flier in comparison to Ae. aegypti, thus able to disperse further. Our results suggest the opposite in that Ae. albopictus females are weaker fliers in 
comparison to Ae. aegypti females, which fly on average $4.5 \mathrm{~km}$ in $16 \mathrm{~h}$ flight mill trials [17] and up to $14 \mathrm{~km}$ when flown to exhaustion [30]. These parameters were determined in different laboratories and conditions, and a direct comparison of their flight performance should be done in the same laboratory under identical conditions, as accomplished in a recent study of the flight performance of wild $v s$. transgenic Ae. aegypti males [20].

The flight behaviour of Ae. albopictus has been investigated in the field. Mark-release-recapture experiments revealed the mean distance travelled by females (or males) was approximately $200 \mathrm{~m}$, with maximal flight ranges between 50 to $325 \mathrm{~m}$, as determined 4 to 23 days after release [31-33]. Another approach was to feed females with rubidium so that it would be incorporated into eggs and readily detected at oviposition sites during one gonotrophic cycle [34]. The suitability of this approach was proven in a pioneering field study with Ae. aegypti which flew similar distances compared to Ae. albopictus [35]. Studies with Ae. albopictus revealed that within one gonotrophic cycle (4 and 6 days in duration) females always reached the periphery of the inspected area. The most distant point was $280 \mathrm{~m}$ or $800 \mathrm{~m}$ from the release site, respectively [27,29], thus indicating that females likely disperse beyond this range. In addition, it was shown that Ae. albopictus readily disperses vertically, e.g., rubidium was detected in eggs on the ground floor as well as $60 \mathrm{~m}$ above ground after the release of marked females in the middle of the building [29]. Notably, guidelines for focal vector control of Dengue postulate that most of the relevant vector mosquitoes, including Ae. albopictus, stay within $100 \mathrm{~m}$ of the place where they emerged [36], but field studies [29,35] and our laboratory study show that Ae. albopictus females can disperse over a much greater distance — up to several kilometres within a few days, thus encountering a greater number of hosts and breeding sites. Future studies may require both flight mill and field trials with laboratory-reared and wild Ae. albopictus to better estimate their ability to disperse and survive as pathogen vectors.

\section{Acknowledgments}

This study was supported by an NIH grant (AI33108) to M.R.B. and a personal grant to C.K. (Forschungskredit of the University of Zürich, 4974). Special thanks to Alexander Mathis for his helpful suggestions after critically reading the manuscript. We are indebted to Daniel Hegglin for assistance with the statistical analysis.

\section{Conflict of Interest}

The authors declare no conflict of interest.

\section{References}

1. Yee, D.A. Tires as Habitats for Mosquitoes: A Review of Studies within the Eastern United States. J. Med. Entomol. 2009, 45, 581-593.

2. Takumi, K.; Scholte, E.J.; Braks, M.; Reusken, C.; Avenell, D.; Medlock, J.M. Introduction, scenarios for establishment and seasonal activity of Aedes albopictus in The Netherlands. Vector Borne Zoonotic Dis. 2009, 9, 191-196. 
3. Adhami, J.; Reiter, P. Introduction and establishment of Aedes (Stegomyia) albopictus skuse (Diptera: Culicidae) in Albania. J. Am. Mosq. Control Assoc. 1998, 14, 340-343.

4. Romi, R.; Majori, G. An overview of the lesson learned in almost 20 years of fight against the “tiger" mosquito. Parassitologia 2008, 50, 117-119.

5. Wymann, M.N.; Flacio, E.; Radczuweit, S.; Patocchi, N.; Lüthy, P. Asian tiger mosquito (Aedes albopictus) — A threat for Switzerland? Euro Surveill. 2008, 13, pii: 8058.

6. Schaffner, F.; Hendrickx, G.; Scholte, E.J.; Medlock, J.M.; Angelini, P.; Ducheyne, E. Development of Aedes albopictus risk maps; Technical report for European Centre for Disease Prevention and Control: Stockholm, Sweden, 2009; pp. 1-45.

7. Sprenger, D.; Wuithiranyagool, T. The discovery and distribution of Aedes albopictus in Harris County, Texas. J. Am. Mosq. Control Assoc. 1986, 2, 217-219.

8. Gratz, N.G. Critical review of the vector status of Aedes albopictus. Med. Vet. Entomol. 2004, 18, 215-227.

9. Bonilauri, P.; Bellini, R.; Calzolari, M.; Angelini, R.; Venturi, L.; Fallacara, F.; Cordioli, P.; Angelini, P.; Venturelli, C.; Merialdi, G.; et al. Chikungunya virus in Aedes albopictus, Italy. Emerg. Infect. Dis. 2008, 14, 852-854.

10. Lambrechts, L.; Scott, T.W.; Gubler, D.J. Consequences of the expanding global distribution of Aedes albopictus for dengue virus transmission. PLoS Negl. Trop. Dis. 2010, 4, e646.

11. Reiter, P.; Fontenille, D.; Paupy, C. Aedes albopictus as an epidemic vector of chikungunya virus: Another emerging problem? Lancet Infect. Dis. 2006, 6, 463-464.

12. Gould, E.A.; Gallian, P.; de Lamballerie, X.; Charrel, R.N. First cases of autochthonous dengue fever and chikungunya fever in France: From bad dream to reality! Clin. Microbiol. Infect. 2010, $16,1702-1704$.

13. Gage, K.L.; Burkot, T.R.; Eisen, R.J.; Hayes, E.B. Climate and Vectorborne Diseases. Am. J. Prev. Med. 2008, 35, 436-450.

14. Sutherst, R.W. Global change and human vulnerability to vector-borne diseases. Clin. Microbiol. Rev. 2004, 17, 136-173.

15. Talbalaghi, A.; Moutailler, S.; Vazeille, M.; Failloux, A.B. Are Aedes albopictus or other mosquito species from northern Italy competent to sustain new arboviral outbreaks? Med. Vet. Entomol. 2010, 24, 83-87.

16. Kaufmann, C.; Briegel, H. Flight performance of the malaria vectors Anopheles gambiae and Anopheles atroparvus. J. Vector Ecol. 2004, 29, 140-153.

17. Briegel, H.; Knusel, I.; Timmermann, S.E. Aedes aegypti: Size, reserves, survival, and flight potential. J. Vector Ecol. 2001, 26, 21-31.

18. Briegel, H.; Waltert, A.; Kuhn, A.R. Reproductive physiology of Aedes (Aedimorphus) vexans (Diptera: Culicidae) in relation to flight potential. J. Med. Entomol. 2001, 38, 557-565.

19. Clements, A.N. Flight. In The Biology of Mosquitoes: Sensory, Reception, and Behaviour; CABI: Oxford, UK, 1999; Volume 2, pp. 286-332.

20. Bargielowski, I.; Kaufmann, C.; Alphey, L.; Reiter, P.; Koella, J. Flight performance and teneral energy reserves of two genetically-modified and one wild-type strain of the yellow fever mosquito Aedes aegypti. Vector Borne Zoonotic Dis. 2012, 12, 1053-1058. 
21. Briegel, H.; Timmermann, S.E. Aedes albopictus (Diptera: Culicidae): Physiological aspects of development and reproduction. J. Med. Entomol. 2001, 38, 566-571.

22. Rowley, W.A.; Graham, C.L.; Williams, R.E. A flight mill system for the laboratory study of mosquito flight. Ann. Entomol. Soc. Am. 1968, 61, 1507-1514.

23. SPSS Software. Available online: www.spss.com (accessed on 3 July 2013).

24. Müller, G.C.; Xue, R.D.; Schlein, Y. Differential attraction of Aedes albopictus in the field to flowers, fruits and honeydew. Acta Trop. 2011, 118, 45-49.

25. Xue, R.D.; Barnard, D.R.; Müller, G.C. Effects of body size and nutritional regimen on survival in adult Aedes albopictus (Diptera: Culicidae). J. Med. Entomol. 2010, 47, 778-782.

26. Gary, R.E., Jr.; Foster, W.A. Effects of available sugar on the reproductive fitness and vectorial capacity of the malaria vector Anopheles gambiae (Diptera: Culicidae). J. Med. Entomol. 2001, $38,22-28$.

27. Honorio, N.A.; Silva Wda, C.; Leite, P.J.; Goncalves, J.M.; Lounibos, L.P.; Lourenco-deOliveira, R. Dispersal of Aedes aegypti and Aedes albopictus (Diptera: Culicidae) in an urban endemic dengue area in the State of Rio de Janeiro, Brazil. Mem. Inst. Oswaldo Cruz 2003, 98, 191-198.

28. Kawada, H.; Takemura, S.Y.; Arikawa, K.; Takagi, M. Comparative study on nocturnal behavior of Aedes aegypti and Aedes albopictus. J. Med. Entomol. 2005, 42, 312-318.

29. Liew, C.; Curtis, C.F. Horizontal and vertical dispersal of dengue vector mosquitoes, Aedes aegypti and Aedes albopictus, in Singapore. Med. Vet. Entomol. 2004, 18, 351-360.

30. Rowley, W.A.; Graham, C.L. The effect of temperature and relative humidity on the flight performance of female Aedes aegypti. J. Insect Physiol. 1968, 14, 1251-1257.

31. Marini, F.; Caputo, B.; Pombi, M.; Tarsitani, G.; della Torre, A. Study of Aedes albopictus dispersal in Rome, Italy, using sticky traps in mark-release-recapture experiments. Med. Vet. Entomol. 2010, 24, 361-368.

32. Lacroix, R.; Delatte, H.; Hue, T.; Reiter, P. Dispersal and survival of male and female Aedes albopictus (Diptera: Culicidae) on Reunion Island. J. Med. Entomol. 2009, 46, 1117-1124.

33. Bellini, R.; Albieri, A.; Balestrino, F.; Carrieri, M.; Porretta, D.; Urbanelli, S.; Calvitti, M.; Moretti, R.; Maini, S. Dispersal and survival of Aedes albopictus (Diptera: Culicidae) males in Italian urban areas and significance for sterile insect technique application. J. Med. Entomol. 2010, 47, 1082-1091.

34. Rozeboom, L.E.; Rosen, L.; Ikeda, J. Observations on oviposition by Aedes (S.) albopictus Skuse and A. (S.) polynesiensis Marks in nature. J. Med. Entomol. 1973, 10, 397-399.

35. Reiter, P.; Amador, M.A.; Anderson, R.A.; Clark, G.G. Short report: Dispersal of Aedes aegypti in an urban area after blood feeding as demonstrated by rubidium-marked eggs. Am. J. Trop. Med. Hyg. 1995, 52, 177-179.

36. WHO. Dengue: Guidelines for Diagnosis, Treatment, Prevention and Control; WHO: Geneva, Switzerland, 2009.

(C) 2013 by the authors; licensee MDPI, Basel, Switzerland. This article is an open access article distributed under the terms and conditions of the Creative Commons Attribution license (http://creativecommons.org/licenses/by/3.0/). 